\title{
A INDUSTRIALIZAÇÃO E A CRISE DO PODER
}

\section{Sedi Hirano ${ }^{a}$}

Produtor de mercadorias de exportação, o Brasil sofre as injunções da demanda do mercado externo há quase quatro séculos. O reflexo, em razão da crise do sistema exógeno-importador, fez-se sentir por longos anos, com aparente mecanicidade, o que, aliás, quase sempre serviu de justificativa para o argumento de que a sociedade brasileira era fruto do sistema econômico externo dominante, ou seja, do capitalismo internacional, sendo, portanto, uma economia reflexa. E de fato o era. Entretanto, é preciso desmistificar as causas imediatas, emergidas da crise do capitalismo "trustificado", notando que as tensões sociais e políticas surgem como consequência de um processo mais amplo, engendrado não só pelo modo de produção capitalista, mas também pela coexistência de um sistema pré-industrial. Antes da crise internacional de 1929, existia no país uma tênue industrialização que satisfazia, de maneira discreta, o mercado de consumo em adendo às importações, havendo com isso condições para a industrialização, em face da implantação de mão de obra assalariada - principalmente a dos imigrantes - e também da acumulação capitalista proporcionada pela economia cafeeira, desde o fim do século 19 (CARDoso, 1960).

Por isso:

o quadro explicativo mais amplo só se completa quando se considera que, anteriormente, a economia brasileira sofrera modificações que se referiam ao próprio regime social de produção: intensificou-se o processo de organização capitalista da vida econômica - a produção passou a ser com base na mão de obra livre e apoiava-se em uma estrutura mercantil generalizada, o que supõe a criação de um mercado consumidor de mão de obra (CARDOSo, 1960, p. 41).

Alguns países acompanharam a grande crise do capitalismo norte-americano entre os anos de 1929 e 1930. Não foi o caso do Brasil, onde ela atuou como uma força propulsora dos fatores de produção até então amortecidos pela concorrência com os produtos importados. Os acontecimentos de 1929 possibilitaram, assim, a revitalização da pequena indústria nacional, que se viu impelida a responder às

a Professor de Sociologia I para o $3^{\circ}$ ano noturno. Regime Especial de Trabalho, 03/01/1964. 
pressões do mercado consumidor frente à carência da importação. Contudo, não se deve exagerar, afirmando que houve um aumento da "propensão ao consumo", pois a taxa de exploração elevada não permitia a emergência de consumidores com alto poder aquisitivo (RANGeL, 1963). Desse modo, é a pressão de consumidores privados pela crise que possibilita o desenvolvimento do processo de industrialização em São Paulo e em outras regiões do Centro Sul (PrADo JR., 1962)ํ.

Dessa expansão surge a ampliação do mercado pelo uso das forças produtivas disponíveis, em estado de desemprego ou em escala de subemprego, principalmente entre os imigrantes, que trabalhavam nas grandes fazendas de café e caminhavam em direção aos centros urbanos, além dos pequenos agricultores - potencialmente, os futuros trabalhadores das cidades. Diversificava-se, assim, a divisão social do trabalho.

Logo, do ponto de vista econômico, o Brasil passa da situação de consumidor de produtos externos, com certo grau de imprevisibilidade causado por crises cíclicas, a consumidor de mercadorias internamente produzidas. Beneficiam-se disso, de forma ampla, os setores em processo de industrialização, em fase de grande expansão. Em outras palavras, o país passa da procura externa inelástica, com preços oscilantes, para a procura interna elástica, com preços crescentes. De agroexportador desloca-se a emergente civilização urbano-industrial, prejudicando, em parte, os setores exportadores (mas não completamente, pois havia a política de valorização do café) (FurTADo, 1963).

A partir de 1930, diversifica-se, portanto, o emprego da mão de obra livre que se transfere do campo à cidade, aumentando, em decorrência, a redistribuição de renda, com maximização da exploração capitalista (RANGEL, 1963).

O surto de desenvolvimento econômico, entretanto, não se dá de forma contínua, em parte pela falta da capacidade de importação ocasionada pelo desequilíbrio do comércio externo, com tarifas cambiais manipuladas, sem planejamento, que visavam atender apenas aos grupos econômicos nacionais e estrangeiros. Além disso, deve-se também levar em consideração aqueles investimentos estrangeiros que usufruem de grandes lucros, sorvendo com isso os dividendos acumulados pela exportação de produtos primários. Frente a tais fatores, trata-se de um desenvolvimento que se dá através de "surtos de crescimento descontínuos" (CARDoso, 1962; PrAdo JR., 1962, sendo exatamente a descontinuidade econômica - fenômeno específico de países de economia do tipo "colonial” agroexportador e de

1 O autor aborda a penetração capitalista no campo de culturas como algodão e hortaliças em São Paulo e a cultura diversificada de trigo, do arroz e de outros produtos alimentícios no Rio Grande do Sul. Vide também Schilling (1959). 
incipiente industrialização - o fator que desencadeia instabilidade econômica e crise político-social.

Visto que a industrialização é impulsionada pela utilização de técnicas modernas, com o emprego de capital e da força de trabalho livre, dentro de um processo histórico inovador, ela representa a civilização urbano-industrial em um estágio bem avançado em relação à exploração pré-capitalista das riquezas naturais, pois emergem na sociedade brasileira, a partir da relação de produção capitalista moderna, novos valores e padrões de conduta, condizentes com a situação de cada um na estrutura "societária", em que predominam os valores racionais, libertando-se dos laços "comunitários" tradicionais a que se ligam os antigos agricultores.

A civilização urbano-industrial, entretanto, conforme delineado anteriormente, cria uma série de êmulos capazes de amortecer a consciência do "novo proletariado" - que se incorpora ao sistema à procura de ascensão social - e, em outro nível do comportamento, a adesão do proletariado à ideologia burguesa, $\mathrm{o}$ que produz uma reificação da ordem social como um todo, sugerindo estabilidade e permanência "naturais", próprias e inerentes ao sistema capitalista, exatamente em seu núcleo mais dinâmico, na esfera das relações sociais de apropriação" (IANNI, 1963, p. 78 e 79).

Tendo sido, portanto, o desenvolvimento econômico um processo não homogêneo, mas um complexo heterogêneo - em que muitas vezes a própria burguesia, da mesma forma que o proletariado, encontra-se fragmentada em sua maneira de conceber a realidade socioeconômica e política -, não é de se estranhar que, no momento atual (IANNI, 1963, p. 79), a própria burguesia não seja capaz de coordenar, em um todo harmônico, o projeto que trace sua ascensão no poder de maneira absoluta, com dominância de todos os fatores que direta ou indiretamente interfiram no processo industrial. Isso acontece porque a burguesia "limita-se a examinar a superfície diretamente perceptível” (LuKacs, 1958, p. 15-16), sendo, portanto, incapaz de compreender o verdadeiro sentido da história. Na medida em que somente capte as manifestações superficiais da realidade, ela será por isso incapaz de ter a visão globalizadora dos fenômenos sociais, deixando-se levar pelas mistificações do real como ele se apresenta, em grande parte manipuladas por interesses alienígenas que atuam como elemento dissolvente dos valores "nacionalistas", interferindo de fato na realidade brasileira.

Tal incapacidade da burguesia urbano-industrial de compreender a realidade a leva a tomar atitudes completamente contraditórias, pois existe um desnível insolúvel entre o projeto a ser executado e o plano de execução. Aceita-se o projeto que preconiza a desinflação e o desenvolvimento a partir da restrição ao crédito, que é 
sua alma mater na fase atual, para continuar investindo. Desse impasse surge a incapacidade de levar a execução de qualquer plano à risca, pois o controle da realidade econômica é incompatível com os interesses imediatos de lucro daquele grupo, visto que controlar a realidade econômica, por sua vez, significa utilizar a acumulação capitalista em setores vitais e talvez pouco rentáveis no início. Tal medida provoca o espanto da burguesia urbano-industrial. No entanto,

numa economia de fato planificada estes objetivos passam a nortear a atividade econômica do país a partir do momento em que o Plano é aceito. Todo o mecanismo econômico é preparado para realizar os objetivos do Plano. Numa economia capitalista não. Os meios de produção pertencem a indivíduos ou pequenos grupos que os fazem funcionar para os seus interesses e objetivos individuais (SINGER, 1963, p. 6).

É o que vemos na fase atual. Elabora-se um plano trienal que preconiza uma série de metas a serem atingidas, mas já de antemão elas são prejudicadas pela própria incompreensão dos diversos setores industriais, que não agem de forma coordenada em defesa de tais interesses: o interesse particular suplanta, em um regime de capitalismo competitivo, os interesses gerais. Desse modo, as mudanças estruturais produzidas pela emergência do capitalismo urbano-industrial chocam-se com a falta de objetividade da burguesia face aos problemas estruturais, que urgem medidas decididas para superar a atual fase de inquietação social. A burguesia não sabe o que fazer com a reforma agrária, urbana, universitária e quiçá a reforma constitucional que, como está, permite alguns privilégios a grupos restritos da sociedade brasileira.

Isso ocorre pelo fato de ser a burguesia nacional, em princípio, representante do mundo moderno. Por essa natureza dualista, ela tende a acomodar-se com o imperialismo econômico internacional e com os resquícios "semifeudais" dos representantes do setor arcaico de algumas regiões do Brasil (E. VARGA, 1963, p. 155).

Reiterando alguns pontos, a descontinuidade do desenvolvimento industrial fez com que surgissem na realidade brasileira várias tensões e conflitos de ordem diversa, quanto à forma de manifestação, como a revolta dos sargentos, as greves reivindicatórias por melhores salários, o pedido do estado de sítio e outras inquietações sociais de ordem mística. Mas, em toda manifestação, afigura um problema crucial: a implosão dos entraves que obstam a transformação capitalista da economia brasileira. 
Quem executará as medidas necessárias para que a civilização urbano-industrial se desenvolva com continuidade? As crises apontam que o Brasil se encontra em um impasse. Resta, portanto, saber que rumo tomará a sociedade brasileira nos próximos decênios.

Enfaticamente, acrescenta-se que a atual crise político-social só poderá ser entendida quando inserida no contexto global, em que o modo de produção capitalista e a correlação das forças políticas nacionais e internacionais façam fluir sintomas indicadores da situação transitória de uma economia em processo de desenvolvimento industrial.

Não se processa a industrialização de forma articulada, contínua e homogênea - o que não é característica do capitalismo. Antes, ela é circunscrita às áreas da região Centro-Sul, com disparidades econômicas regionais abissais, as quais, a seu turno, são resultantes do desenvolvimento histórico do capitalismo, que produziu, na realidade político-social do Brasil, grupos econômicos díspares, cujos porta-vozes na política são os senadores, os deputados federais e estaduais e os vereadores, ora transformados em defensores dos interesses desses grupos, nos quais se inserem. Ao defendê-los, defendem-se.

Sendo a eleição presidencial uma empreitada que requer grande mobilização de capitais, em associação com determinados grupos de interesses, sobretudo em razão da extensão territorial do país, que potencia os custos de campanha, torna-se difícil que candidatos não influentes e de poder econômico limitado alcancem a primeira magistratura.

Visto serem os grupos empresariais modernos e arcaicos os grandes detentores do capital e os proprietários dos meios de comunicação, o candidato presidencial que recebe seu apoio financeiro quase sempre vence as eleições. Por outro lado, $o$ poder econômico da região Centro-Sul somente predomina em relação ao candidato presidencial por razões óbvias. No tocante aos representantes do povo no Congresso Nacional, predomina a manipulação do eleitorado pelos grupos locais, resultando deste processo um legislativo heterogêneo, que traduz as diversidades regionais. Ideias e valores, modos de pensar e agir historicamente divergentes colocam-se face a face. A mentalidade patriarcal e patrimonialista se defronta com a mentalidade urbano-industrial. Por esse motivo, o Congresso é composto 
por pessoas com mentalidades díspares, que se refletem nos comportamentos dos políticos, em que o etnocentrismo e a mentalidade paroquial e tradicionalista, muitas vezes, suplantam a atitude racional em face dos problemas nacionais.

Enquanto isso, o Executivo procura imunizar-se dos preconceitos regionais e provincianos, valendo-se da impossibilidade de cada região apresentar "seu" candidato presidencial.

Ao inserir os partidos políticos em tal contexto global, percebe-se claramente que as atitudes e opiniões dos representantes do povo se manifestam de acordo com sua situação no processo, perdendo, assim, o teor "ideológico" que cada representante, pelo menos em tese, dá ao partido. Em consequência, os interesses locais frequentemente superam os interesses nacionais e partidários como um todo. Vê-se daí que os partidos, como as siglas e brasões de famílias oligárquicas dominantes, simplesmente ostentam um valor nominal, diluindo-se o "modelo" ideológico e doutrinário de cada partido conforme a ação manifesta dos grupos de interesse suprapartidários que refletem o poder das grandes famílias. O PTB do Norte e do Nordeste, por exemplo, em muitos aspectos é completamente diferente do PTB do Centro-Sul, que, por sua vez, encontra-se ainda subdividido em duas facções: o grupo compacto mais ideológico e o grupo fisiológico aderente. Diante dessa realidade, verifica-se que a maioria partidária é uma maioria mitificada (artificial), ou seja, ela constitui, por vezes, uma falsa ou real ostentação de poder e prestígio político, dando-se, coerentemente ou contraditoriamente, por tudo isso, a ação inconsequente das legendas partidárias que apoiam o Executivo, enfraquecendo-o ou fortalecendo-o conjunturalmente e levando-o, frequentemente, às crises políticas sucessivas.

O poder partidário majoritário inexiste de fato, sendo simplesmente uma maioria nominal. Se não o fosse, as crises seriam enquadradas dentro de um esquema político racional, de um projeto emergido da realidade social e capaz, portanto, de ser implementado com diretrizes bem definidas, que refletissem os interesses da sociedade brasileira como um todo. Os partidos políticos no Brasil são, em consequência, mero suporte jurídico para garantir o registro de candidatos dos vários grupos de interesse econômico.

Naturalmente, a descontinuidade do processo industrial também se manifesta nas ações desconexas do Congresso Nacional, atomizado em duas casas:

A omissão do nosso executivo da ação parlamentar entrega a iniciativa das leis a caprichos individuais, o que torna a legislação esparsa, muitas vezes supérflua quando não demagógica e desligada das verdadeiras necessidades públicas. A 
atividade mais frequente se cifra em concessões de vantagens salariais ou outras, aos servidores públicos civis e militares e às demais classes de assalariados. Fora disto, as leis de certa importância mais frequente são as de prorrogação anual de proteção aos inquilinos, da elevação de tributos, também rotineiramente periódica, para fazer face (sempre de modo insuficiente) ao alargamento do desequilíbrio orçamentário e ainda segundo os outros: "O senado pouco participa dele" (Melo Franco, 1963, p. 3).

Nota-se com clareza que a função do Congresso Nacional é meramente "legislativa”, mais corporativo-administrativa, e procura dar continuidade ao sistema, visando fundamentalmente

dar o reconhecimento de utilidade pública a tal ou qual associação de longínquo município, isentar do pagamento de imposto aduaneiro a imagem da santa destinada à igreja do arraial de catingas, ou ainda conceder pensão especial à viúva do mata-mosquito ou do velho jornalista. Percorre-se a ordem do dia de qualquer das casas do Congresso, em seção de rotina, e se verá que a grande massa das deliberações versa sobre pequenos atos administrativos (Melo Franco, 1963).

É isso o Congresso Nacional, segundo o testemunho de um parlamentar que participou e participa ainda daquela instituição democrática há mais de uma década ${ }^{2}$. Enquanto o país atravessa um estágio de transição social e econômica, necessitando de medidas racionais e urgentes que venham ao encontro das necessidades sociais, o Congresso Nacional se perde com questiúnculas de menor importância.

Destarte, o Poder Legislativo brasileiro não acompanhou o Brasil em sua trajetória histórica, interferindo, com seu gênio criativo, pela adoção de um projeto de ação capaz de quebrar as áreas de estrangulamento geradas pela industrialização desigual e descontínua. É o que se vê: o Poder Executivo só consegue maioria parlamentar para sustentar-se no poder a partir de uma política conciliatória, tentando, com isso, adotar medidas adequadas. Entretanto, a própria ação política presidencial gera o emperramento da máquina administrativa, pois a conciliação

2 Laski (1957, p. 55) comenta a inconveniência da existência de duas câmaras: "Uma segunda câmara eleita não está tampouco em melhor situação. Se ela é eleita ao mesmo tempo e pelo mesmo procedimento que a primeira, refletirá meramente a sua composição; se o é em épocas diferentes e, ainda mais, com procedimento distinto, estorvará o trabalho do governo em exercício e com a sua condição de privilégio limitado, se inclinará demasiado a proteger os interesses que aquele reduzido se acentue". 
na política significa ceder para governar. Esse recuo quebra qualquer ação verdadeira e ideologicamente coerente para a redefinição da situação presente. Em vista disso, objetiva-se um poder sem poder, pois sua existência é apenas "jurídica”: a conciliação o demonstra. Concilia-se para ficar, e não para executar as medidas que a industrialização necessariamente exige, rumo à superação da estrutura "pré-industrial" e patrimonialista. Emerge dessas condições a crise que redundou na revolta dos sargentos e, mais precisamente, no pedido do estado de sítio. Destaque-se que, sendo a industrialização ainda recente no Brasil, suas linhas de ação ainda não se encontram plenamente definidas. Portanto, vê-se um sistema em "pleno desenvolvimento, não tendo ainda produzido todos os seus efeitos, nem permitindo que alguns produtos sociais mais típicos se exprimam abertamente" (IANNI, 1963, p. 17).

Esse é exatamente o contexto de emergência das sucessivas crises mencionadas, que se manifestam de uma forma isolada, quando mistificadas. Todavia, a matriz fundamental do processo radica exatamente nas mudanças estruturais que estão ocorrendo na realidade brasileira, com a introdução do modo de produção capitalista. Decorre daí o surgimento de uma civilização urbano-industrial que carrega em seu bojo as tensões sociais e os conflitos que se verificam nas áreas de determinadas instituições: o conflito e o antagonismo ou, ainda, o desajustamento entre valores e padrões, por um lado nacionais e antinacionais, por outro patrimoniais, tradicionais e rotinizados, que são, em consequência, componentes normais das condições de vida nos ambientes urbanizados do país (IANNI, 1963).

\section{III}

Como ficou delineado, as manifestações da crise são decorrências da formação do capitalismo industrial, que se processa ora de maneira lenta, ora rápida e, em geral, descontínua. Ao mesmo tempo, o Congresso Nacional se rotiniza em suas regras procedimentais, "legislando" em torno de pequenos atos administrativos, incompatíveis com o processo de racionalização burocrática emergente. Por outro lado, a Constituição Brasileira, formalizada após a ditadura Vargas, delimita demasiadamente a ação do Poder Executivo, o qual encontra espaço para a proposição de medidas políticas concretas, quando concilia interesses díspares em uma ação conjunta entre o Legislativo e o Executivo. Ação essa que pretende traduzir os interesses gerais da nação. Frequentemente, a ação do Poder Executivo é tolhida por alguns itens constitucionais que constrangem a ação presidencial no Congresso Nacional. Por outro lado, como já vimos, os parlamentares estão voltados 
para nichos provinciais de pequena relevância. À luz desses fatos, encontram-se os sargentos, militares subalternos na hierarquia militar, que reivindicam os direitos que a democracia representativa propicia a todos os cidadãos brasileiros: a participação ativa e efetiva na vida política brasileira e a possibilidade de serem eleitos para cargos de representação política, que são vetados pela mencionada Constituição.

Entretanto, nesse período de consolidação do processo de desenvolvimento industrial, o aspecto aparentemente isolado da revolta dos sargentos ganha uma dimensão que ultrapassa a esfera castrense e penetra no campo da ampliação dos direitos políticos: o direito de votar e ser votado. Esta rebelião reivindicatória dos militares subalternos adquire (nos primórdios da década de 1960) uma dimensão política nova, interferindo de modo multilateral e multidimensional na realidade brasileira e desencadeando outros movimentos políticos em outros segmentos militares, em um ritmo crescente de radicalização de posições entre as forças em embate. Nesse sentido, a rebelião significou e significa ainda a negação da realidade política institucionalizada, isto é, a negação da inelegibilidade consagrada pela Constituição do Brasil de 1946. Os segmentos militares de baixo escalão passam a fazer parte das forças de pressão popular, entrando na esfera que congrega um feixe de reivindicações chamadas "reformas de base", necessárias para desencadear um desenvolvimento mais equilibrado e planejado da economia brasileira, por meio da inclusão de segmentos excluídos. As ações dos militares subalternos são, portanto, qualitativamente idênticas, apesar da virulência com que se desencadearam suas lutas por direitos políticos - e que as diferencia daquelas dos demais segmentos.

Acrescenta-se ainda que a industrialização sempre desponta em meio a uma estrutura incompatível com a nova ordem. Consequentemente, no início, ela não produz uma superestrutura capaz de redefinir a situação presente. A redefinição ocorre de maneira lenta e desigual, em face da descontinuidade e heterogeneidade com que se desenvolvem as forças produtivas no Brasil, pois a população nacional adquire sua "personalidade básica" no interior de uma estrutura em que os padrões e os valores sociais são canalizados para a preservação do status quo. Todavia, à medida que a população pertencente aos setores pré-capitalistas incorpora-se à moderna sociedade urbano-industrial, sua mentalidade vai sendo moldada conforme os padrões e valores emergentes elaborados a partir de 1930 - como, por exemplo, a consciência de que os direitos dos trabalhadores são garantidos pela Legislação Trabalhista, que é alimentada, em muitos deles, pelo mito do êxito pessoal, etc. 
Verifica-se cristalinamente que o operário recém-egresso do campo incorpora-se quase passivamente a um contexto político-social previamente traçado pela civilização urbano-industrial, onde se dá o amortecimento de sua consciência política. Hoje (1963), de modo geral, o que acontece no movimento operário não é mais do que a simples greve de reivindicação salarial, manipulada pelos organismos elaborados pelo governo para aumentar a "propensão para o consumo", greve essa que é provocada pela depreciação do salário frente à inflação e, talvez, para pressionar os atores políticos contrários a uma política de industrialização realizada sob o controle do Estado. Na época da ditadura Vargas, as greves eram voltadas às medidas jurídicas que estabeleciam a relação de convivência entre a burguesia e o proletariado, em termos "legais", e não mais em termos policiais, como era anteriormente. Observa-se ainda que, na atualidade (1963), alguns setores sindicais vão aos poucos redefinindo-se para quebrar os vínculos criados pelo Estado-Novo, na tentativa de construir um sindicato mais propenso a defender os interesses da classe operária, em um sentido mais amplo e revolucionário. Porém esse movimento é facilmente desmobilizado pelo governo, que monopoliza postos-chave no Estado, como o Ministério do Trabalho, a Confederação Nacional dos Trabalhadores na Indústria (CNTI), o Comando Geral dos Trabalhadores (CGT), etc., que estão sob o controle direto da Presidência da República.

No contexto da industrialização descontínua, emergem ações de caráter revolucionário que significam a antecipação do futuro por meio de um projeto viável, como expressão da contingência presente. Conforme entende Sartre (196ob), a contingência presente consiste em negar, na ação, o presente e concretizar o futuro, ou seja, realizar um projeto por meio da ação revolucionária consciente. É, portanto, pela cisão, pela negação dos valores tradicionais que perpetua o passado na ação do presente e que se pode vislumbrar o futuro como um projeto possível, implodindo a continuidade do passado no presente e no futuro.

A consciência de futuro dissolve a visão mistificada da realidade como sendo imutável. A burguesia, no entendimento de Sartre, não tem nenhuma perspectiva revolucionária, enquanto o revolucionário, a partir da condição presente, nega a realidade, formulando um projeto de futuro. Assim, todos aqueles que querem e, consequentemente, lutam para mudar a situação do presente transcendem, logicamente, à "situação contingência", transpondo-a, negando seus valores pela ação e utilizando, se necessário, a violência coletiva - ou ainda, como no caso dos sargentos, transformando-se em franco-atiradores. Mas é preciso notar que a esse movimento faltou o respaldo da ação coletiva cristalizado em um projeto revolucionário, visto que ele era desprovido de diretrizes claramente definidas. Desse 
modo, a revolução metamorfoseou-se em uma "rebeliãozinha" de um pequeno grupo de militares subalternos, que tomaram alguns pontos de Brasília para depois devolvê-los aos donos dos privilégios.

No entanto, a importância do fato não se radica "na quartelada" ou em uma simples rebelião, mas nos reflexos que produziu em forças sociais que lutavam de forma não coesa, mas estavam decididas a mudar o rumo da história. Várias organizações que surgiram no processo de industrialização manifestaram-se prontamente, apoiando o movimento. As oposições também se apresentaram, engrossando o apoio a ele. O mais importante, a tal respeito, é o fato de que um grupo de militares subalternos polarizou a sociedade brasileira em seu conjunto - na medida em que as forças de pressão popular não são frutos ou produtos de apenas um grupo -, visto que a movimentação de rebeldia foi gerada por um processo mais amplo. Isso poderia transformar-se em uma força motriz revolucionária, em cuja estrutura estaria o processo de industrialização que abriu alternativas para a participação de múltiplos atores como sujeitos da história.

Da negação de um dos itens da Constituição explode a rebelião e o Congresso Nacional se mostra incapaz de propor soluções condizentes e em consonância com os fatores novos ${ }^{3}$. Essa situação é acrescida pela de insegurança do Poder Executivo, provocada por uma série de manifestações ofensivas, coordenadas por forças conservadoras contra o governo, por setores ligados aos setores tradicionais e alienígenas. Desponta nesse cenário a figura do Senhor João Goulart, solicitando o estado de sítio: uma arma excepcional para tomar medidas excepcionais, que de fato urgia tomar, pois a onda de boatos e inquietações sociais avassalava o Poder Executivo. No entanto, as bases de sustentação do poder estavam corroídas pela conciliação incessante - e por isso faltou o apoio das forças com que se supunha contar.

Porém, face aos acontecimentos imprevisíveis, medidas acauteladoras foram tomadas. O Congresso Nacional, inoperante para os tempos que corriam, estava em questão, juntamente com o Poder Executivo. Os políticos estavam prestes a perder seus privilégios; grupos poderosos sentiram-se inseguros. O estado de

3 Harold J. Laski, em Introducción a la política, diz: "a experiência do sistema de grupos (...), quando atua, o único procedimento para controlar um Legislativo é organizar uma coalizão de grupos (partidos) que produza uma maioria capaz de dominá-lo, e o resultado disto é substituir a manobra à responsabilidade e privar a política daquela coerência e amplitude que a capacita para ser julgada efetivamente" (p. 52). Mais adiante, acrescenta a inconveniência da existência de duas câmaras: "qualquer um que recorde o tempo que necessitou, na Inglaterra, para levar ao Estado Legal medidas transcendentais como a reforma eleitoral, a autonomia Irlandesa ou da educação nacional, se sentirá propenso a pedir uma técnica para acelerar a aprovação da legislação do que retardá-la”. 
sítio pedia a cabeça de dois governadores, mas o fulcro da questão não estava na personalidade desses homens públicos. O imprevisível se afigurava como um fator de insegurança e ainda de maior intranquilidade do que antes, pois a prisão desses dois políticos não significava o enclausuramento, mas sim o aguçamento da crise. Outra dúvida assaltava: quem seria o interventor, um militar ou um civil? O que fariam os interventores após a deposição dos governadores? E quem seria mais atingido, após os dois primeiros?

Por outro lado, o sítio votado seria um fato consumado, sendo o processo irreversível. E votar o estado de sítio seria a negação dos parlamentares como políticos, ou seja, negar a si mesmos e a seus privilégios, como representantes do povo, "a serviço do povo". O sítio, por outro lado, seria a manifestação de poder de um grupo - portanto, não seria viável despojar o Congresso de seu poder. Por tudo isso, era óbvio que o pedido não seria deferido, pois ninguém votaria contra os interesses já estabelecidos. Em consequência, nesse ponto, os interesses individuais dos congressistas coincidiam com o interesse geral dos deputados e senadores, resultando, ipso facto, na retirada do Congresso Nacional. Diante disso, para que se efetivasse o estado de sítio, faltou o apoio necessário e obrigatório das forças populares. Pode-se afirmar que a conciliação do governo teve um efeito dissolvente e se desvinculou da simpatia popular, em razão de suas ações vacilantes durante toda a trajetória presidencial, acentuada, sobremaneira, naquela ocasião de crise aguda na gestão do Estado.

Depara-se, no momento atual (1963), com o seguinte: o governo não é suficientemente forte para executar as reformas necessárias e está longe de configurar-se como um capitalismo de Estado politicamente poderoso, para colocar em ação um planejamento racional que se traduza em desenvolvimento equilibrado. $\mathrm{O}$ Congresso Nacional, por outro lado, está totalmente incapacitado, por motivos já expostos, para legislar em favor de uma política racionalmente desenvolvimentista, dado que a industrialização foi implantada de forma concentrada em algumas regiões do território nacional - principalmente no Sul-Sudeste -, abarcando uma parte restrita da região central do Brasil. O Congresso, apequenado por motivos particulares, não tem visão para estabelecer um projeto de Estado.

Aventamos, enfim, que a industrialização e o modo de produção capitalista desenvolver-se-ão em um processo descontínuo, em que setores-chave interferirão no processo de modernização do país.

Pode-se afirmar que a política econômico-financeira do Ministério da Fazenda é afetada por injunções de fatores internos e externos de múltiplas procedências, muitos dos quais incontroláveis, como o desenvolvimento e a crise das economias 
centrais, que afetam a demanda de produtos primários de exportação, e uma completa ausência de uma política econômica de caráter nacional, afetada por uma variedade de demandas particularistas.

Concluindo, a industrialização no Brasil far-se-á de uma maneira segmentada, descontrolada, sem planejamento no longo prazo. Isso produzirá crises que irão inquietar os segmentos da sociedade brasileira nos próximos anos. $\mathrm{O}$ desenvolvimento da civilização urbano-industrial não está, ainda, suficientemente avançado para forçar um curso normal de seu processo em benefício de toda a coletividade. Por sua vez, o Congresso Nacional continuará atuando como uma força de entravamento do processo de modernização, por fatores já explicitados, visto que a existência de uma multiplicidade de partidos políticos, sem ideologia, reflete a fobia democrática, na prática, inconsequente, e na ação, descoordenada.

Todavia, se não for criado nenhum dispositivo tendente a amainar a radicalização entre a burguesia e o proletariado, ocorrerá, nos próximos decênios, o fortalecimento das forças de pressão popular que emergirão como o único partido de cunho ideológico, em sentido estrito, com componente de ação revolucionária.

Por fim, os reflexos da competição internacional entre o socialismo e o imperialismo terão uma importância considerável no desencadeamento da Revolução Brasileira.

\section{REFERÊNCIAS BIBLIOGRÁFICAS}

CARdoso, Fernando Henrique. Condições Sociais da Industrialização de São Paulo. p. 38 e 39. Brasiliense, 28, março-abril de 1960

CARDoso, Fernando Henrique. Proletariado no Brasil: situação e comportamento. Revista Brasiliense, São Paulo, n. 41, p. 98, 1962.

E. VArga. Capitalismo do século XX. Editora Civilização Brasileira; Coleção BUP, 1963. p. 155 (nota de rodapé).

Furtado, Celso. Formação econômica do Brasil. 5. ed. Rio de Janeiro: Fundo de Cultura, 1963. p. 225.

IANNI, Octávio. Industrialização e desenvolvimento social no Brasil. Polarizações da Ideologia do Empreendedor; Civilização Brasileira, 1963. p. 78 e 79, capítulo VI.

LASKi, Harold J. Introducción a la política. Argentina - Siglo Veinte: Colección Panoram, 1957. p. 55.

LukACs, George. La crisis de la filososfía burguesa. Argentina/Buenos Aires: Editora Siglo Veinte; Colección Panorama, 1958. p. 15 e 16. 
Melo Franco, Afonso Arinos. A crise e o Poder Legislativo. Jornal do Brasil, domingo, o6/10/1963, Caderno Especial, p. 3.

Prado JR., Caio. Crise em marcha. Brasiliense, n. 42, p. 161-198, jul.-ago. 1962.

RANGEL, Ignácio. A inflação brasileira. Rio de Janeiro: Ed. Tempo Brasileiro, 1963. p. 30 e 31.

SARTRE, J. P. La república del silencio: estudios políticos y literarios. Buenos Aires: Editora Losada, 1960a.

La filosofia de la revolution. Buenos Aires: Editora Losada, 196ob. p. 113.

Schilling, Paulo. Trigo: trigo e o latifúndio no Rio Grande do Sul. Rio de Janeiro: Iseb, 1959. (Recursos naturais do Brasil, v. 16.)

Singer, Paul. Análise do plano trienal. Rio de Janeiro: Editora Universitária (UNE), 1963. p. 6. 